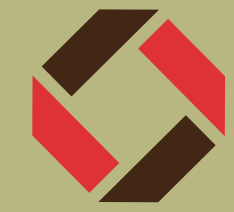

\title{
Alana Ogata credits the role of mentorship in her career decisions
}

\section{By Xaimara Santiago-Maldonado}

$\mathrm{C}$ an you imagine a Pap smear on-astick test? This is just one of the ideas that Dr. Alana Ogata, the newest faculty member of the Department of Chemistry and the Department of Chemical and Physical Sciences at the University of Toronto, envisions for her career as a researcher. But she did not always know that becoming a researcher, teacher, and mentor was her mission. "When I got to college, I did not have a major going in or a plan for my career," she told MRS Bulletin. At the College of William \& Mary, Ogata ventured into taking a general chemistry course with a friend even though she was not particularly attracted to the subject. Interestingly, the laboratory component of the course was a turning point for her.

"All of the sudden, things just really clicked for me. Doing experiments in person, with my hands, helped me understand the theory and it was exciting to be creating things in the lab," she said.

After declaring chemistry as her major, she met her first research mentor, Dr. Kristin Wustholz, at a department seminar, and joined her lab shortly after that.

"I did not know anything about chemistry research or a career as a faculty member. But in Dr. Wushtolz's lab, all I knew was that I was really excited about research and I loved doing it," she said. Wustholz's group focused on spectroscopic techniques for solar energy conversion. In fact, it was Wustholz who prompted her to consider graduate school to pursue a $\mathrm{PhD}$ degree in chemistry.

Unlike many incoming graduate students in the chemistry department, when she arrived at the University of California, Irvine (UC Irvine), Ogata did not have a faculty member in mind as a thesis advisor. She took this opportunity to rotate in different laboratories and explore new research areas. She eventually chose Dr. Reginald Penner's lab to work on electrochemical sensors for cancer diagnostics. "I was really excited about the project, and I wasn't intimidated that I had no previous experience in electrochemistry," she said. Besides the research project, another important factor that drove her to choose Penner's lab was the support environment that he promoted. Ogata said, "I felt comfortable asking any question and Dr. Penner was just an excellent teacher and mentor."

In the course of her $\mathrm{PhD}$ program, Ogata's career plans changed a few times. Initially, she wanted to work in industry. Then, she became interested in entrepreneurship and startup companies. It was not until the summer before graduating, while teaching a class, that something just clicked. "Most graduate students were not interested in academia and I thought neither was I," she said, "but when I started teaching again it made sense, because I realized that I not only love research, but I also love mentoring and teaching." After graduation, she did a short-term postdoctoral position with Dr. Joe Patterson at UC Irvine, whose work focuses on materials science and cryogenic electron microscopy (cryo-EM). "He was a new professor at the time and helping him start a new lab really solidified that I wanted to be a faculty and run my research group," she said.

As a postdoctoral fellow, Ogata joined Brigham and Women's Hospital at Harvard Medical School. She started working in the Department of Pathology, under the mentorship of Dr. David Walt, to work on ultrasensitive protein measurements using the single-molecule array (Simoa) technique. "I switched fields again and that was really tough. I just remember being so stressed the first four months learning completely new things. You come from your PhD, where you get very comfortable with where you are and then you have to start all over again. You are surrounded by a lot of smart high-quality scientists and that can be extremely intimidating," she said. Nonetheless, as a person who has always been driven by what excites her, Ogata focused on learning the new methods and techniques.

During the first few months in this postdoctoral position, Ogata learned how to use Simoa, which is an ultrasensitive method for protein detection that is orders of magnitude more sensitive than standard immunoassay techniques.

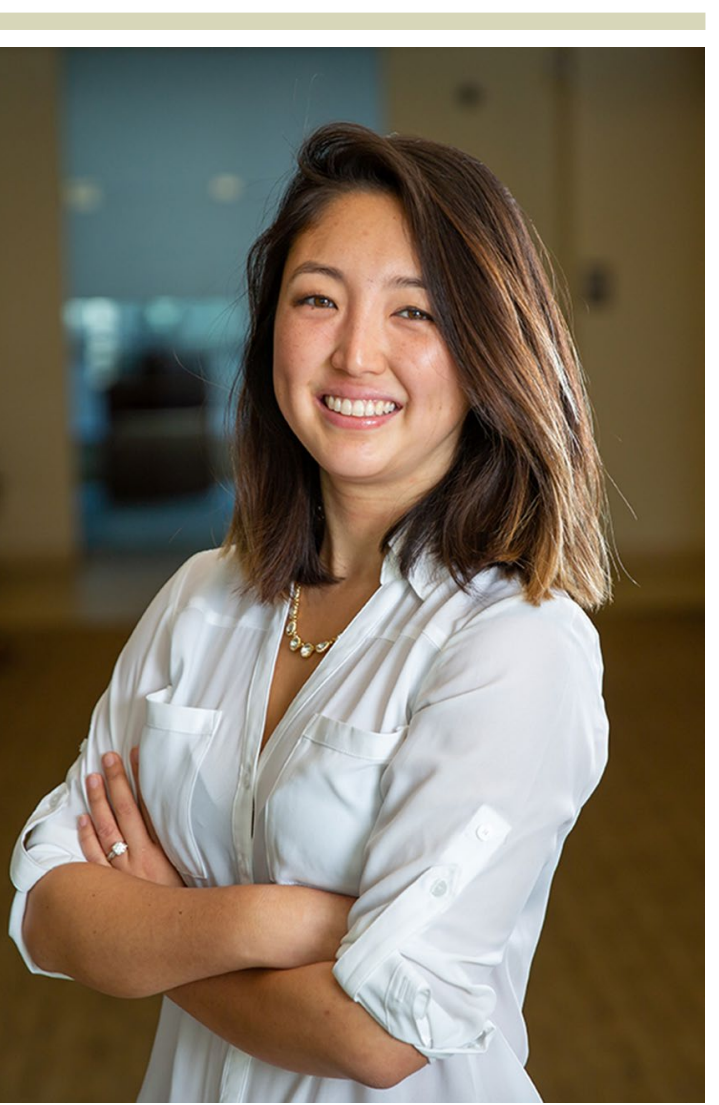




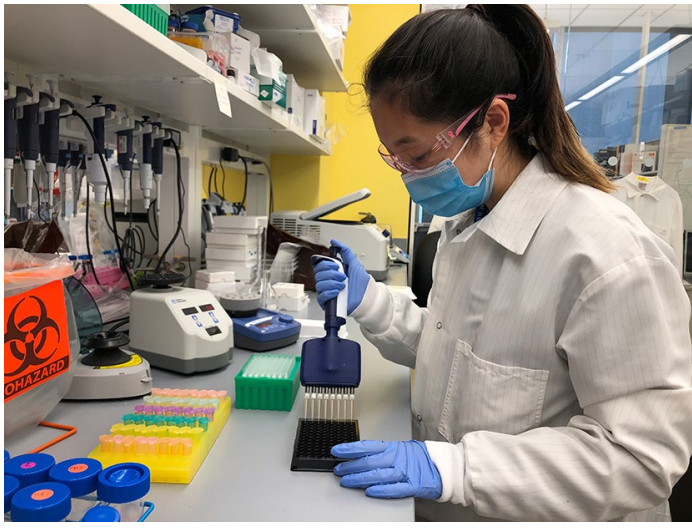

She aimed to use this technique to measure proteins in single cells and look for proteins associated with different categories of diseases. However, her plans were drastically changed when the COVID-19 pandemic hit.

"Essentially all those projects stopped once the pandemic started; I never had the chance to go back and finish $80 \%$ of them," Ogata said. Around two weeks after the initial shutdown, she and her colleagues were granted access to the laboratory due to some COVID19 grants. "In terms of the research and science, it was one of the most exciting projects I have ever worked on. The amount of research we were doing was amazing," she said. "We were pumping out data faster than ever."

Despite their excitement to be working in groundbreaking research related

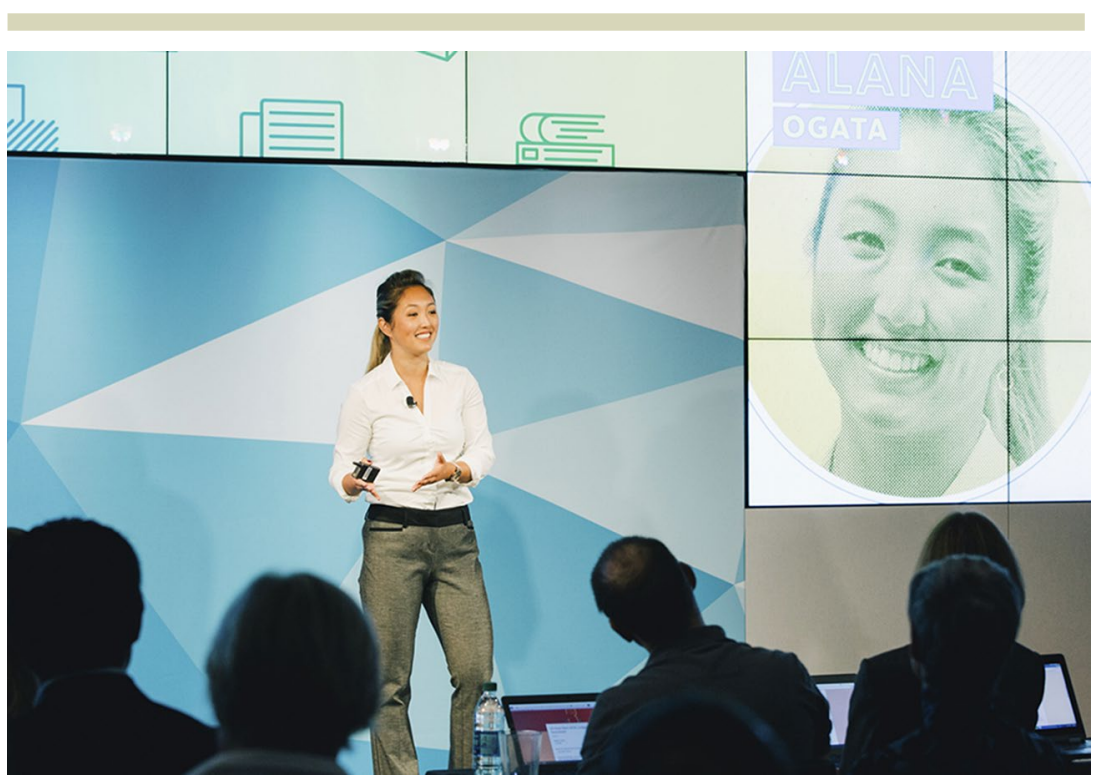

become more empathetic toward myself and more empathetic to the future students who work for me," she said.

Ogata successfully finished her postdoctoral experience, and her work and collaborations have resulted in at least eight publications. She then pursued her goal of becoming a faculty member, a process that was also affected by the pandemic. "There was no way for me to visit the campus, so the hardest thing was deciding whether or not I should go somewhere that I never visited," she said. Notwithstanding, she accepted a faculty position at the University of Toronto starting in the fall 2021.

Ogata's research laboratory will focus on development of bioanalytical technologies using bioinspired nanomaterials, including complementary and single-molecule bioanalytical sensors for ultrasensitive protein measurements and electrochemical biosensors for point-ofcare applications. She aims to combine her knowledge of analytical chemistry, materials sciences, and clinical chemistry to develop technologies that can be used for diagnostics, primarily focusing on gynecological diseases. "My research program is now based on a combination of all my previous research experiences. And I want to use these technologies to innovate in the area of women's health; there is still so much we do not know about women's health and a lot of gynecological diseases go undiagnosed," she said.

In addition to research, now that she is leading her own group, Ogata aims to focus on high-quality mentorship. "I've chosen all of my research experiences primarly based on the quality of mentorship, in addition to how excited I was about the research," she said. Her mentorship style is based on empathy, learning, and accountability, and she takes into consideration the individuality of each student to help them achieve their goals.

Ogata told MRS Bulletin, "I am here to teach, first and foremost. I believe that we are not here to just do research, make people do research, and hope they learn along the way. Learning must be at the center of it and I am here to help students reach their potential." 